1. MBBS, FCPS, FMAS. Associate Professor, Department of Surgery Khyber Teaching Hospital, Peshawar.

2. MBBS

Resident Surgeon Department of Surgery Khyber Teaching Hospital, Peshawar, Pakistan.

3. MBBS, FCPS

Assistant Professor Department of Surgery Khyber Teaching Hospital, Peshawar, Pakistan.

4. MBBS

Resident Surgeon Department of Surgery Khyber Teaching Hospital, Peshawar, Pakistan.

5. MBBS

Resident

Department of Surgery

Khyber Teaching Hospital,

Peshawar, Pakistan.

6. MBBS

Resident

Department of Surgery

Khyber Teaching Hospital,

Peshawar, Pakistan.

Correspondence Address: Dr. Junaid Zeb

Doctor Lounge, Surgical C Ward, Khyber Teaching Hospital,

Peshawar, KPK, Pakistan.

junaidzeb100@gmail.com

Article received on:

04/12/2018

Accepted for publication:

25/03/2019

Received after proof reading:

$28 / 08 / 2019$

\section{LAPAROSCOPIC TRANSPERITONEAL ADRENALECTOMY: THE GOLD STANDARD TREATMENT.}

\begin{abstract}
Mohammad Zarin', Maham Qazi', Sayed Asad Maroof ${ }^{3}$, Junaid Zeb ${ }^{4}$, Muhammad Ishfaq Ahmad ${ }^{5}$, Maria Mir Jan ${ }^{6}$

ABSTRACT... Objectives: The aim of our study was to evaluate safety and outcomes of laparoscopic transperitoneal adrenalectomy in the treatment of adrenal tumors in terms of peri operative complications. Moreover we have also focused on frequency of tumors presented with adrenal masses. Study Design: Cross sectional study. Setting: Khyber Teaching Hospital, Peshawar Pakistan. Period: $20^{\text {th }}$ October 2014 to $30^{\text {th }}$ January 2018. Material and Methods: Total of 43 patients were included in study after informed consent to participate in the study. Data was collected by predesigned questionnaire and analyzed by SPSS 20. Results: A total of 43 Laparoscopic transperitoneal adrenalectomies were performed, predominantly for pheochromocytomas (19 cases). Out of all cases operated 24 laparoscopic transperitoneal adrenalectomies were performed on the right side and 19 on the left side. According to the tumor localization, the mean operative time was $90 \pm 9.5$ minutes. Intraoperative complications occurred in five cases $11.6 \%$. The common intraoperative complication was intraoperative bleeding (9.3\%). The intraoperative complication rate on the right side was $9.3 \%$ due to intra-operative hemorrhage and the corresponding rate on left was $2.3 \%$ due to inra-operative diaphragh tear. In one case $(2.3 \%)$ we could not control intraoperative hemorrhage laparoscopically and it got converted to open surgery for control of bleeding, whereas rest of the three cases with intraoperative bleeding were controlled by identifying the bleeding vessel and clipping it. Post-operative complications occurred in 7 patients (16.27\%). Conclusion: Laparoscopic transperitoneal Adrenalectomy is safe, feasible procedure with decrease morbidity and early post operative recovery and discharge from hospital with no mortality.
\end{abstract}
Key words: Ganglioneuroma, Laparoscopic Transperitoneal Adrenalectomy, Pheochromocytoma.

Article Citation: Zarin M, Qazi M, Maroof SA, Zeb J, Ahmad MI, Jan MM. Laparoscopic transperitoneal adrenalectomy: The gold standard treatment. Professional Med J 2019; 26(9):1440-1444. DOI: 10.29309/TPMJ/2019.26.09.1843

\section{INTRODUCTION}

Laparoscopic adrenalectomy is the gold standard treatment for patients with adrenal tumors. ${ }^{1}$ The first endoscopic technique was introduced to perform adrenalectomy in $1992 .^{2}$ There are a number of laparoscopic approaches available including retroperitoneal approach, transperitoneal approach while the transperitoneal approach is the most commonly practiced one, ${ }^{3,4}$ any of them showing strengths and Weaknesses. The choice of any approach depends on different parameters such as surgeon's expertise, tumor size and hemodynamic stability of the patient. These methods can be employed to treat both functioning as well as non-functioning adrenal disease. ${ }^{5}$
Robotic adrenalectomy and posterior retroperitoneal adrenalectomy have outstanding results for benign and medium sized $(<6 \mathrm{~cm})$ tumors. Like any minimally invasive approach they have the advantage of Low patient morbidity with short hospital post-operative stay, improved cosmesis and a rapid recovery. ${ }^{6}$ Lateral transperitoneal adrenalectomy can be challenging in patients with previous abdominal Surgeries because of post-operative adhesions, which make it difficult to work. ${ }^{7}$

Studies have shown that laparoscopic transperitoneal adrenalectomy is a safe, effective and feasible procedure in the treatment of adrenal gland tumors which has led to the innovative 
change in the treatment modality of adrenal gland tumors. $^{8,9}$ In several studies it has been shown that minimally invasive technique is superior to the old conventional open surgery with regards to safety, efficacy and complications rate..$^{10,11}$ According to a study by Lubikowski et $\mathrm{al}^{12}$ the benefits of retroperitoneal approach in contrast to transperitoneal approach are more because of limited injuries to visceral organs and reduced intestinal complications.

The aim of our study is to evaluate safety and outcomes of laparoscopic transperitoneal adrenalectomy in the treatment of adrenal pathologies in terms of peri operative complications. Moreover we have also focused on frequency of tumors presented with adrenal masses.

\section{MATERIAL AND METHODS}

This cross sectional study was conducted at Khyber Teaching Hospital, Peshawar Pakistan, from $20^{\text {th }}$ October 2014 to $30^{\text {th }}$ January 2018 , on a total of 43 patients. 29 male patients and 14 female patients with age range of 18-55 years were part of the study. Patients were confirmed to have an adrenal tumor by imaging with tumor size not more than $8 \mathrm{~cm}$ were included in our study while tumor being operated previously or had any contraindication for pneomoperetonium were excluded from study. The study was performed after approval from the hospital ethics committee. All patients included in study gave informed consent to participate in the study before the operation, in which benefits as well risks of surgery along with conversion to open surgery in case of any difficulty arising during operation were explained to the patients.

All of these patients received a complete laboratory investigations, including urinary vanillylmandelic acid level (VMA), ACTH, plasma and urinary metanephrine levels, 24 hours urinary cortisol levels, low and high dose dexamethasone suppression tests, 17-hydroxycorticosteroids and Aldosterone/Renin Ratio. Imaging evaluations such as Ultrasound, computed tomography, MRI and MIBG scans were performed to determine nature, localization and diameter of the mass.
A lateral position was selected for all patients. A $30^{\circ}$ laparoscope was used through a $10-\mathrm{mm}$ port, the other three ports were placed collaterally to costal margin starting from median line, placing the last one near the end of the $12^{\text {th }}$ rib. We performed the dissection with either hook or harmonic scalpel. The adrenal gland is dissected from all its attachments and the resected tumor is placed in the endobag for retrieval with slightly widening of one of the trocar incisions. The pressure of the pneumoperitonuem largely prevents parenchymal bleeding.

After surgery all patients were followed up for a period of 6 months. Data was collected by doctor using predesigned questionnaire and analyzed by SPSS 20.

\section{RESULTS}

A total of 43 Laparoscopic transperitoneal adrenalectomies were performed, predominantly for pheochromocytomas (19 cases). Out of all 43 cases operated, 29 patients were males and 14 were female patients. Of the total 43 Laparoscopic Transperitoneal Adrenalectomies carried out, 24 were performed on the right side and 19 on the left side. Mean operative time was $90 \pm 9.5$ minutes.

Intraoperative complications occurred in five cases $11.6 \%$. Out of these five cases 4 had intraoperative complication on the right side and one on the left side. The right sided complicated cases suffered intraoperative bleeding. Intraoperative blood transfusion was required in 4 cases out of all the cases operated. In one case we could not control intraoperative hemorrhage laparoscopically and it got converted to open surgery for control of bleeding, whereas rest of the three cases with intraoperative bleeding were controlled by identifying the bleeding vessel and clipping it. One case on the left side had intraoperative diaphragm rupture. The patient with diaphragm tear was treated with laparoscopic repair of diaphragm and tube thoracostomy. The common intraoperative complication was intraoperative bleeding 9.3\%. The intraoperative complication rate on the right side was $9.3 \%$ and the corresponding rate on left was $2.3 \%$. 
In the post operative period, 7 patients (16.27\%) developed complications. These complications were atelectasis in 2 patients (4.6\%) followed by wound site infection in 3 patients $(6.9 \%)$ and 2 patients $(4.6 \%)$ suffered from post operative fever due to abdominal collection which was treated with ultrasound guided aspiration. Only one case (2.3\%) got converted to open surgery.

The demographic data and clinical outcome showed that the leading indication for adrenalectomies out of all cases was Pheochromocytoma (44.1\%). Second most common indication for adrenalectomy was Ganglioneuroma (27.9\%). Detail given in Table-I.

All cases with pheochromocytoma were started on pharmacological blockade 2 weeks priorly to the surgery, which was administered under the care of the endocrinology service team. All cases of Pheochromocytoma (19/43) were transferred to High definition unit for close blood pressure monitoring. The detail of Hisopathology report given in Table-I.

\begin{tabular}{|l|c|c|}
\hline Histopathology Report & $\begin{array}{c}\text { No. } \\
\text { Patients (n) }\end{array}$ & $\begin{array}{c}\text { Percentage } \\
\text { (\%) }\end{array}$ \\
\hline Pheochromocytoma & 19 & 44.1 \\
\hline Ganglioneuroma & 12 & 27.9 \\
\hline Adrenocortical Cancer & 3 & 6.97 \\
\hline Adrenal Adenoma & 2 & 4.65 \\
\hline Adrenal Epithelial Cyst & 3 & 6.97 \\
\hline Lipoma & 2 & 4.65 \\
\hline Myelolipoma & 1 & 2.32 \\
\hline Adrenal Pseudocyst & 1 & 2.32 \\
\hline
\end{tabular}

Table-I. Histopathology reports of different types of tumors presented with adrenal masses.

There was no mortality. All of the patients were discharged uneventfully. Postoperative average hospital stay was $4 \pm 1.5$ days.

\section{DISCUSSION}

Laparoscopic transperitoneal adrenalectomy was the only technique of laparoscopic adrenalectomy performed in our department in the analyzed period. Among the 43 patients treated with adrenal mass with laparoscopic transperitoneal adrenalectomy our intraoperative complication rate was $11.6 \%$, having intraoperative complication rate on the right side as $9.3 \%$ and the corresponding rate on left as $2.3 \%$. Our results show that laparoscopic transperitoneal adrenalectomy is a safe, effective and technically feasible procedure in the treatment of adrenal masses. In a study by $\mathrm{O}$ Bahadir et $\mathrm{al}^{13}$ it is reported that laparoscopic approach is superior to the open conventional surgery for performing adrenalectomies, they reported transperitoneal approach to be safe with easy identification of structures. In a study by Lubikowski $\mathrm{J}$ et $\mathrm{al}^{12}$, they have stated the advantages of retropertitoneal approach are more due to lesser visceral organs injury. We have noted functioning tumors more frequently than nonfunctioning tumors. Moreover pheochromocytoma was on the top of that in most of the patients presented with adrenal masses. Another study had also reported same results with functioning tumors being more common than non-functioning in case of adrenal masses and pheochromocytoma on top of them. ${ }^{5}$

Our study had mean operative time as $90 \pm 9.5$ minutes, which was comparable to study reported by Chaun-Yu et $\mathrm{al}^{14}$ to be $95 \pm 29$ minutes and Kulis et $\mathrm{al}^{15}$ to be 102 minutes. However the mean time of different centers varies some have reported higher operative time ranges. ${ }^{16,17}$ In another study it is reported that operative time for laparoscopic retroperitoneal approach is shorter than the transperitoneal approach. ${ }^{19}$

In our study intraoperative bleeding was the commonest complication with a rate of $9.3 \%$. In 4 out of 43 cases (9.3\%) of the right sided transperitoneal adrenalectomies we encountered intraoperative bleeding. In 3 cases (6.9\%) we controlled bleeding by identifying and clipping the vessel laparoscopically but one case (2.3\%) got converted to open surgery to control hemorrhage. In a study by Goitein $D$ et $\mathrm{al}^{18}$ it is reported that intraoperative hemorrhage is the most common complication encountered in open as well as laparoscopic adrenalectomy. In a study by $\mathrm{O}$ Bahadir et $\mathrm{al}^{13}$ they have reported intraoperative bleeding complication in 6 out of 66 cases $(9 \%)$ in functioning adrenal tumours 
undergoing laparoscopic adrenalectomies. They have also reported intraoperative hemorrhage in non-functioning tumors undergoing laparoscopic adrenalectomies in 3 out of 34 cases (8.8\%).

\section{CONCLUSION}

Laparoscopic transperitoneal Adrenalectomy is safe, feasible procedure with decrease morbidity and early post operative recovery and discharge from hospital with no mortality. Commonest presentation of adrenal masses was phechromocytoma followed by ganglioneuroma followed by adrenocortical cancer and adrenal epithelial cyst followed by adrenal adenoma and lipoma followed by myelolipoma and adrenal pseudocyst. A multidisciplinary team including endocrinologists, physicians, anesthesiologists and general surgeons is needed for management of adrenal pathology.

\section{ACKNOWLEDGEMENT}

We acknowledge this research work to our Kind and Devoted Head of Department, Prof. Dr. Rooh UI Muqim, Department of Surgery, Khyber Teaching Hospital, Peshawar, Pakistan.

\section{Copyright@ 25 Mar, 2019.}

\section{REFERENCES}

1. Miron A, Giulea C, Nădrăgea M, Enciu O. Laparoscopic partial adrenalectomy. 2017 Jan-Feb; 112(1):77-81.

2. Chen W, Lin W, Han D-J, Liang Y. Lateral retroperitoneoscopic adrenalectomy for complicated adrenal tumor larger than $\mathbf{5}$ centimeters. Afri Health Sci. 2017; 17(1): 293-300. https://dx.doi.org/10.4314/ ahs.v17i1.36.

3. Gagner M, Pomp A, Heniford BT, Pharand D, Lacroix A. Laparoscopic adrenalectomy: lessons learned from 100 consecutive procedures. Annals of surgery. 1997 Sep;226(3):238.

4. Duh QY, Siperstein AE, Clark OH, Schecter WP, Horn JK, Harrison MR, Hunt TK, Way LW. Laparoscopic adrenalectomy: comparison of the lateral and posterior approaches. Archives of Surgery. 1996 Aug 1;131(8):870-6.

5. Conzo G , Gambardella C, Candela G, Sanguinetti A, Polistenam A, Clarizia $G$, et al. Single center experience with laparoscopic adrenalectomy on a large clinical series. BMC Surgery; 2018: 18(2):1-7.
6. Conzo G, Tartaglia E, Gambardella C, Esposito D, Sciascia V, Mauriello C, Nunziata A, Siciliano G, Izzo G, Cavallo F, Thomas G, Musella M, Santini L. Minimally invasive approach for adrenal lesions: Systematic review of laparoscopic versus retroperitoneoscopic adrenalectomy and assessment of risk factors for complications. Int J Surg. 2016; 28:118-23.

7. Morris L, Ituarte P, Zarnegar R, et al. Laparoscopic adrenalectomy after prior abdominal surgery. World J Surg 2008; 32: 897-903.

8. Gagner M, Lacroix A, Bolte' E. Laparoscopic adrenalectomy in Cushing's syndrome and pheochromocytoma. N Engl J Med.1992; 327:1033.

9. Higashihara E, Tanaka $\mathrm{Y}$, Horie S, et al. A case report of laparoscopic adrenalectomy. Jap J Urol. 1992; 83:395e400.

10. Scoglio D, Balla A, Pacile` $M$, et al. Laparoscopic transperitonea anterior adrenalectomy. Ann Ital Chir. 2013; 84:411e416.

11. Brunt LM. The positive impact of laparoscopic adrenalectomy on complications of adrenal surgery. Surg Endosc. 2002; 16: 252e257.

12. Lubikowski J, Kiedrowicz B, Szajko M, et al. Laparoscopic adrenalectomy for functioning and non-functioning adrenal tumours. Endokrynol Pol. $2011 ; 62: 512 e 516$.

13. Bahadir O,Akcan A, Emek E, Akyuz M, Sozuer E, Akyildiz $\mathrm{H}$ et al. Laparoscopic surgery in functioning and nonfunctioning adrenal tumors: A single center experience. Asian Journal of Surgery (2015), http:// dx.doi.org/10.1016/j.asjsur.2015.04.009

14. Chuan-Yu S, Yat-Faat H, Wei-Hong D, et al. Laparoscopic adrenalectomy for adrenal tumors. Int $\mathrm{J}$ Endocrinol. 2014; 2014:241854.

15. Kulis T, Knezevic N, Pekez M, Kastelan D, Grkovic M, Kastelan Z. Laparoscopic adrenalectomy: Lessons learned from 306 cases. J Laparoendosc Adv Surg Tech. 2012; 22:22e26.

16. Scoglio D, Balla A, Pacile` $M$, et al. Laparoscopic transperitoneal anterior adrenalectomy. Ann Ital Chir. 2013; 84:411e416.

17. Ali JM, Liau SS, Gunning K, et al. Laparoscopic adrenalectomy: Auditing the $\mathbf{1 0}$ year experience of a single centre. Surgeon. 2012; 10:267e272.

18. Goitein D, Mintz Y, Gross D, Reissman P. Laparoscopic adrenalectomy: Ascending the learning curve. Surg Endosc. 2004; 18:771e773. 
19. Chen W, Li F, Chen D, Zhu Y, He C, Du Y, Tan W. Retroperitoneal versus transperitoneal laparoscopic adrenalectomy in adrenal tumor: A metaanalysis. Surg Laparosc Endosc Percutan Tech. 2013; 23(2):1217.

\begin{tabular}{|c|c|c|c|}
\hline \multicolumn{4}{|c|}{ AUTHORSHIP AND CONTRIBUTION DECLARATION } \\
\hline Sr. \# & Author-s Full Name & Contribution to the paper & Author $=$ s Signature \\
\hline 1 & Mohammad Zarin & Conception and design of study. & \\
\hline 2 & Maham Qazi & $\begin{array}{l}\text { Statistical expertise, abstract } \\
\text { and article writing. }\end{array}$ & \\
\hline 3 & Sayed Asad Maroof & Drafting of the article. & \\
\hline 4 & Junaid Zeb & $\begin{array}{l}\text { Collection and assembly of } \\
\text { data. }\end{array}$ & \\
\hline 5 & M. Ishfaq Ahmad & $\begin{array}{l}\text { Data collection and drafting of } \\
\text { the article. }\end{array}$ & \\
\hline 6 & Maria Mir Jan & $\begin{array}{l}\text { Data collection and drafting of } \\
\text { the article. }\end{array}$ & \\
\hline
\end{tabular}

